\title{
Abciximab in the management of acute myocardial infarction with ST-segment elevation: evidence-based treatment, current clinical use, and future perspectives
}

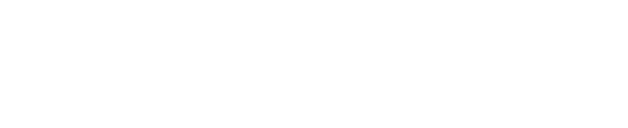

\section{Artur Dziewierz' \\ Tomasz Rakowski' \\ Dariusz Dudek ${ }^{2}$}

'2nd Department of Cardiology, Jagiellonian University Medical College, Krakow, Poland; ${ }^{2}$ Department of Interventional Cardiology, Jagiellonian University Medical College, Krakow, Poland
Correspondence: Artur Dziewierz 2nd Department of Cardiology, Jagiellonian University Medical College, 17 Kopernika St, 31-50I Krakow, Poland Tel $+48 \quad 124247180$

Fax +48 I 2424 7I 84

Email adziewierz@gmail.com

\begin{abstract}
Introduction of antiplatelet agents has contributed substantially to improve the outcome of patients with acute coronary syndromes. Meta-analysis of the studies on abciximab administration during primary percutaneous coronary intervention (PCI) for acute ST-segment elevation myocardial infarction (STEMI) has clearly confirmed the mortality benefit associated with intravenous bolus and infusion of abciximab compared to placebo. Recently, introduction of new oral $\mathrm{P}_{2} \mathrm{Y}_{12}$ inhibitors (prasugrel, ticagrelor), with a faster and more pronounced antiplatelet effect, have decreased the use of abciximab even in patients with STEMI. However, recent studies have shown a delayed onset of antiplatelet effect of new oral antiplatelet drugs in the setting of STEMI, especially in patients with hemodynamic compromise. Thus, the use of abciximab as an intravenous agent should be strongly considered when oral $\mathrm{P}_{2} \mathrm{Y}_{12}$ inhibitors might fail or cannot be given before primary PCI for STEMI. An additional benefit of abciximab administration was reported when abciximab was given early, before primary PCI, compared to typical periprocedural use. To the contrary, no clear clinical benefit was confirmed for intracoronary administration of abciximab compared with intravenous administration. Future studies should focus on the role of abciximab given on top of new oral P2 $\mathrm{Y}_{12}$ inhibitor (prasugrel, ticagrelor) or used as an alternative to an intravenous $\mathrm{P}_{2} \mathrm{Y}_{12}$ inhibitor (cangrelor). Undoubtedly, the results of these studies will change everyday practice of STEMI treatment.
\end{abstract}

Keywords: glycoprotein IIb/IIIa inhibitors, acute myocardial infarction, percutaneous coronary intervention

\section{Introduction}

It is well recognized that platelets play a key role in the pathophysiology of acute coronary syndromes and thrombotic complications of percutaneous coronary intervention (PCI). Introduction of antiplatelet agents, especially the glycoprotein (GP) IIb/IIIa receptor inhibitors, has contributed substantially to improving the outcome of patients with acute coronary syndromes. The prototypical agent abciximab is the Fab fragment of the chimeric human-murine monoclonal antibody 7E3. Abciximab inhibits platelet aggregation by preventing the binding of fibrinogen, von Willebrand factor, and other adhesive molecules to GP IIb/IIIa receptor sites on activated platelets. Antiplatelet effect of abciximab correlates with the degree of GP IIb/IIIa receptor blockade (maximal inhibition of platelets is achieved when $\geq 80 \%$ of GP IIb/IIIa receptors are blocked). The maximal antiplatelet effect is usually present 10 minutes after bolus administration. Abciximab also binds to the vitronectin receptor (on platelets, 
as well as endothelial and smooth muscle cells of the vessel wall) and to the activated Mac-1 receptor (on monocytes and neutrophils). ${ }^{1}$ The recommended dosage of abciximab is a $0.25 \mathrm{mg} / \mathrm{kg}$ intravenous bolus followed by 12 -hour infusion of $0.125 \mu \mathrm{g} / \mathrm{kg} / \mathrm{minute}$.

\section{Abciximab - initial clinical experiences}

Introduction of GP IIb/IIIa inhibitors has changed the daily practice of primary PCI for acute ST-segment elevation myocardial infarction (STEMI). Studies that assessed the value of abciximab during primary PCI for STEMI have shown benefits of such adjunctive pharmacotherapy, mainly driven by reduction of composite clinical end point (death, reinfarction, repeat revascularization). ${ }^{2-5}$ The largest benefit was seen in the reduction of need for urgent repeat revascularization, but a higher risk of bleeding was observed in patients treated with abciximab. Importantly, the rate of bleeding was directly dependent on the administered dose of unfractionated heparin. The significant increase in major bleeding was found in an abciximab group in the ReoPro and Primary PTCA Organization and Randomized Trial (RAPPORT) study with a dose of $100 \mathrm{U} / \mathrm{kg}$ of unfractionated heparin and recommended activated clotting time $($ ACT $)>300$ seconds. $^{2}$ In further trials, both the drug dose (usually $70 \mathrm{U} / \mathrm{kg}$ ) and the recommended ACT (200-300 seconds) were reduced. ${ }^{3,4}$ This influenced the bleeding rate and the significant difference in major bleeding was no longer present. In the largest meta-analysis of studies on abciximab in STEMI, including studies with both primary PCI and fibrinolysis, De Luca et al showed that abciximab administration was associated with a significant reduction in 30-day and long-term mortality in patients treated with primary PCI but not in those receiving fibrinolysis. ${ }^{6}$ The reinfarction at 30 days was reduced in the abciximab group in both primary PCI and fibrinolysis patients. Abciximab administration was associated with an increased risk of major bleeding when combined with fibrinolysis but not with primary PCI. Importantly, abciximab did not result in an increased risk of intracranial bleeding. ${ }^{6}$ The benefit from the routine administration of abciximab during primary PCI in patients with STEMI was confirmed mainly in studies with limited use of clopidogrel, especially given as a $600 \mathrm{mg}$ loading dose. ${ }^{6}$

Most of the studies on the role of GP IIb/IIIa inhibitors in STEMI have focused on abciximab rather than on small-molecule GP IIb/IIIa inhibitors (eptifibatide, tirofiban). Despite the putative advantages of abciximab with respect to inhibition of additional proinflammatory pathways, small-molecule
GP IIb/IIIa inhibitors appear to do as well as abciximab. Two meta-analyses ${ }^{7,8}$ showed similar results between high-dose tirofiban $(25 \mu \mathrm{g} / \mathrm{kg}$ ) (five trials) and eptifibatide (double bolus) (one trial) compared to abciximab among patients with STEMI undergoing primary PCI in terms of angiographic, electrocardiographic, and clinical outcomes. However, none of the trials were adequately powered to evaluate any difference in clinical end points, including mortality. The need for a second bolus (10 minutes after the first one) of eptifibatide may be less user-friendly in the setting of primary PCI. Contrarily to abciximab, dose adjustment is required for small-molecule GP IIb/IIIa inhibitors in patients with chronic kidney disease. ${ }^{9}$ On the other hand, compared with abciximab's long clearance time of 12-24 hours, eptifibatide and tirofiban had a clearance time of only 2-2.5 hours, making them particularly attractive when urgent reversal of their effect was desirable. ${ }^{10}$ Based on American College of Cardiology Foundation/American Heart Association (ACCF/AHA) ${ }^{11}$ and European Society of Cardiology (ESC) STEMI $^{9}$ guidelines, abciximab is recommended with level of evidence A, and eptifibatide (with double bolus) and tirofiban (with a high bolus dose) with level of evidence B. A lower level of evidence for small-molecule GP IIb/IIIa inhibitors is related to a limited amount of comparative data from placebo-controlled clinical trials.

\section{Abciximab - current status}

The use of a combination of unfractionated heparin and GP IIb/IIIa inhibitors in patients with STEMI has decreased over the last few years. ${ }^{12,13}$ Several factors are likely responsible for the decrease.

First, as the result of short- and long-term mortality benefit observed in patients treated with bivalirudin in the HORIZONS-AMI (heparin plus a glycoprotein IIb/IIIa inhibitor versus bivalirudin monotherapy and paclitaxeleluting stents versus bare-metal stents in acute myocardial infarction) study, ${ }^{14,15}$ the use of bivalirudin is preferred over combination of unfractionated heparin and GP IIb/IIIa inhibitors in patients with STEMI, by current guidelines. ${ }^{9,11}$ Also, recently published results of the European Ambulance Acute Coronary Syndrome Angiography (EUROMAX) study ${ }^{16}$ have confirmed the safety and efficacy of bivalirudin administration during transfer for primary PCI. In this study, initiation of bivalirudin before transfer for primary PCI was associated with reduction of non-coronary artery bypass grafting-related major bleeding as well as a composite end point of death and non-coronary artery bypass grafting-related major bleeding as compared to a control group at 30 days. However, in 
HORIZONS-AMI and EUROMAX studies, the higher risk of stent thrombosis was observed in patients treated with bivalirudin, ${ }^{15,16}$ which may suggest the need for optimal antiplatelet coverage during primary PCI for STEMI with more frequent use of GP IIb/IIIa inhibitors. Importantly, despite the inclusion of lower-risk patients, GP IIb/IIIa inhibitors were used in $7.2 \%$ of patients treated with bivalirudin in the HORIZONS-AMI study as a bailout. ${ }^{15}$

Second, the use of abciximab has waned due to the introduction of new $\mathrm{P}_{2} \mathrm{Y}_{12}$ inhibitors (prasugrel, ticagrelor) with a faster and more pronounced antiplatelet effect in comparison to clopidogrel. ${ }^{17-20}$ Both prasugrel (TRial to Assess Improvement in Therapeutic Outcomes by Optimizing Platelet InhibitioN with Prasugrel-Thrombolysis In Myocardial Infarction [TRITON-TIMI-38] study) and ticagrelor (Platelet Inhibition and Patient Outcomes [PLATO] study) were shown to be more clinically effective than clopidogrel in terms of reduction of ischemic events in patients with acute coronary syndromes. ${ }^{21,22}$ Importantly, prasugrel significantly reduced the risk of cardiovascular events in patients with acute coronary syndromes undergoing PCI regardless of whether or not a GP IIb/IIIa inhibitor was used. No impact of GP IIb/IIIa inhibitor on the relative risk of bleeding with prasugrel compared to clopidogrel was observed in the TRITON-TIMI-38 study; ${ }^{23}$ similarly, no interaction between effects of ticagrelor on ischemic and bleeding events and the use of GP IIb/IIIa inhibitors was confirmed in the PLATO study. ${ }^{22}$ However, in both studies, the impact of GP IIb/IIIa inhibitor (versus no GP IIb/IIIa inhibitor) used on top of these new oral drugs was not addressed. ${ }^{22,23}$ The use of prasugrel and ticagrelor is becoming more and more frequent. ${ }^{24,25}$ Unfortunately, new P2 $\mathrm{Y}_{12}$ inhibitors are often used as the replacement for intravenous GP IIb/IIIa inhibitors. Data from the FABOLUS PRO (Facilitation through Aggrastat By drOpping or shortening Infusion Line in patients with STsegment elevation myocardial infarction compared to or on top of PRasugrel given at loading dOse) study ${ }^{26}$ have shown a delayed onset of antiplatelet effect of new oral antiplatelet drugs in the setting of STEMI, and therefore have renewed the interest for GP IIb/IIIa inhibitors. The delayed onset of action of oral antiplatelet drugs may be expected, especially in patients with hemodynamic compromise, ${ }^{27}$ in cardiogenic shock, ${ }^{28}$ or after cardiac arrest in those undergoing mild induced therapeutic hypothermia. ${ }^{29,30}$ Similarly, gastroparesis may impair drug absorption in patients with diabetes mellitus. ${ }^{31}$ In such clinical scenarios, when acetylsalicylic acid and $\mathrm{P} 2 \mathrm{Y}_{12}$ inhibitors might fail or cannot be given before primary PCI for STEMI, the use of abciximab as an intravenous agent should be strongly considered. Finally, some operators believe that mechanical reduction of thrombus burden during primary PCI with aspiration catheters may eliminate the need for the administration of GP IIb/IIIa inhibitors (mechanical instead of pharmacological approach). Pooled analysis of individual data of 2,686 patients enrolled in eleven randomized trials on the use of thrombectomy during primary PCI for STEMI clearly showed the highest mortality benefit when the use of thrombectomy was combined with administration of GP IIb/IIIa inhibitors. ${ }^{32}$ Similarly, in the Intracoronary abciximab and aspiration thrombectomy in patients with large anterior myocardial infarction (INFUSE-AMI) trial, ${ }^{33}$ the highest reduction of the infarct size assessed by cardiac magnetic resonance at 30 days after first anterior wall STEMI was observed when local infusion of abciximab was combined with prior thrombus aspiration. These findings may suggest the need for integration of mechanical and pharmacological strategies to enhance reperfusion and improve clinical outcomes in patients with STEMI.

Abciximab, as a potent antiplatelet agent, decreases the risk of ischemic events, but, on the other hand, may carry an increased risk of bleeding. In a meta-analysis by De Luca et al, abciximab was associated with an increased risk of major bleeding complications when combined with fibrinolysis $(5.2 \%$ versus $3.1 \%, P<0.001)$ but not with primary PCI (4.7\% versus $4.1 \%, P=0.36) .{ }^{6}$ Abciximab did not result in an increased risk of intracranial bleeding $(0.61 \%$ versus $0.62 \%, P=0.62$ ). In a more recent meta-analysis of studies on GP IIb/IIIa inhibitors, administration during primary PCI was associated with higher risk of major bleeding complications $(3.9 \%$ versus $2.6 \%, P=0.0005) .{ }^{34}$ To minimize the risk of bleeding with abciximab, it is important to use a reduced-dose, weight-adjusted heparin regimen under ACT guidance, a weight-adjusted abciximab bolus and infusion, careful vascular access site management, and discontinuation of heparin after PCI. Also, the risk of puncture site-related bleeding may be decreased by the use of a radial approach. In a sub-analysis of the Acute STEMI Treated With Primary Angioplasty and Intravenous $0.5 \mathrm{mg} / \mathrm{kg}$ Lovenox or UFH to Lower Ischemic and Bleeding Events (ATOLL) study on patients with STEMI undergoing primary PCI, the addition of GP IIb/IIIa inhibitors in patients treated with a radial approach was not associated with bleeding liability. ${ }^{35}$ The use of GP IIb/IIIa inhibitors with a radial approach was associated with safer outcomes than using GP IIb/IIIa inhibitors with a non-radial approach. ${ }^{35}$ Importantly, if performed by an experienced radial operator, a radial approach should be preferred over a femoral approach in patients with STEMI. ${ }^{9}$ 
Patients treated with abciximab are also at higher risk of thrombocytopenia (incidence of severe thrombocytopenia [platelet $<50,000$ cells $/ \mu \mathrm{L}$ ] ranged from $0.4 \%$ to $1 \%) .{ }^{36,37}$ Importantly, the risk of thrombocytopenia may be especially elevated in patients receiving abciximab re-administration.

Based on ACCF/AHA guidelines for the management of STEMI, abciximab in conjunction with unfractionated heparin or bivalirudin should be considered in selected patients (class IIa, level of evidence A). ${ }^{11}$ According to ESC STEMI guidelines, GP IIb/IIIa inhibitors should be considered for bailout therapy if there is angiographic evidence of massive thrombus, slow or no reflow, or a thrombotic complication (class IIa, level of evidence C). ${ }^{9}$ Routine use of a GP IIb/IIIa inhibitor as an adjunct to primary PCI performed with unfractionated heparin may be considered in patients without contraindications (class IIb, level of evidence B). ${ }^{9}$

\section{Other abciximab \\ administration strategies}

Based on classic studies, abciximab is typically given as intravenous bolus during the PCI procedure, followed by intravenous infusion. However, different approaches, including bolus-only (versus bolus plus infusion), early (versus periprocedural), or intracoronary (versus intravenous) administration are a matter of debate.

\section{Bolus-only abciximab administration}

Recommendations for intravenous bolus and infusion administration of abciximab is based on the The Evaluation of 7E3 for the Prevention of Ischaemic Complications (EPIC) study, which showed superiority of bolus abciximab plus infusion compared with bolus alone. ${ }^{36}$ However, a recent study showed that withholding abciximab maintenance infusion does not impair platelet inhibition in patients receiving a $600 \mathrm{mg}$ loading dose of clopidogrel. ${ }^{38}$ Similarly, Christ et al have shown that intracoronary abciximab bolus-only administration with oral P2Y ${ }_{12}$ inhibitor (600 mg of clopidogrel or $60 \mathrm{mg}$ of prasugrel) initiation effectively inhibited overall platelet reactivity for at least 48 hours, which brings the value of continuous abciximab infusion into question. ${ }^{39}$ The bolus-only strategy has the potential to improve the safety profile of abciximab (lower risk of bleeding) at reduced costs; however, there is no study confirming the clinical benefits of a bolus-only strategy.

\section{Early abciximab administration}

Since primary PCI is the preferable method of reperfusion, it is very important to provide such treatment to as many patients with STEMI as possible. However, patient transfer to a primary PCI center can cause logistical problems that result in treatment delay. In recent years, efforts have been made to overcome this limitation with logistics improvements and additional pharmacological strategies. After ADMIRAL (Abciximab before Direct angioplasty and stenting in Myocardial Infarction Regarding Acute and Long-term follow-up) trial results, ${ }^{3}$ attention was focused on the optimal time of abciximab administration. In this study, clinical benefit of abciximab over placebo at 30 days and 6 months was especially pronounced in patients receiving abciximab before transfer to a primary PCI center. Importantly, in multivariable analysis, early abciximab administration was found to be a predictor of better outcome. However, this study was not focused on the role of early abciximab administration (only $26 \%$ of patients were randomized before transfer to a primary PCI center) and this was just post hoc observation. ${ }^{3}$ Based on first, nonrandomized studies on early abciximab administration, it was suggested that early abciximab administration may increase the rate of patent infarct-related artery (IRA) before intervention and may be beneficial for outcome. In the Glycoprotein Receptor Antagonist Patency Evaluation (GRAPE) and ReoPro in acute MI (ReoMI) studies, patent IRA on baseline angiography was observed in $40 \%-50 \%$ of patients treated with early abciximab. ${ }^{40,41}$

After initial experiences, a large number of randomized studies comparing early and late (during PCI) abciximab administration were performed. ${ }^{42-53}$ Most of these were powered for surrogate end points, ie, IRA patency before angiography and myocardial reperfusion parameters before and after PCI (electrocardiographic ST-segment elevation resolution, angiographic myocardial blush grade). ${ }^{42-50}$ Most of the studies showed that early abciximab administration is associated with a higher rate of early IRA patency and better myocardial reperfusion parameters before and after $\mathrm{PCI},{ }^{42-46}$ but some showed a benefit only before $\mathrm{PCI}^{47,48}$ or even no beneficial effect of early abciximab administration (minority). ${ }^{49,50}$ In some studies, infarct size and left ventricular function were assessed, showing, for the most part, beneficial effects of early abciximab administration on those parameters, ${ }^{44,51,52}$ but negative results ${ }^{53}$ were also reported.

The abovementioned studies, ${ }^{42-50}$ were underpowered to assess clinical end points; hence, much attention was focused on the Facilitated Intervention with Enhanced Reperfusion Speed to Stop Events (FINESSE) trial, ${ }^{54}$ which was a double-blind, placebo-controlled study, with randomization to combination-facilitated PCI (reteplase, abciximab), abciximab-facilitated PCI, or primary PCI. However, enroll- 
ment in the FINESSE trial was slow (from 2002 to 2006), and was stopped before the planned enrollment of 3,000 patients had been achieved. Additionally, a substantial proportion of patients were enrolled once in a PCI center, rather than before transfer. The FINESSE trial showed no clinical benefit of early abciximab administration, despite a higher rate of early IRA patency as compared to late abciximab administration. ${ }^{54}$ However, in the sub-analysis of FINESSE results, Herrmann et al showed improved survival at 1 year after facilitation of PCI in high-risk patients presenting to a spoke hospital within 4 hours of symptom onset (symptomto-randomization time). ${ }^{55}$ In the meantime, based on previously described smaller studies, early abciximab administration before transfer to a catheter laboratory was introduced as routine therapy in various European STEMI networks. Based on experiences of those European STEMI networks, the idea of registry introduction was born. The European Registry on Patients With ST-Elevation MI Transferred for Mechanical Reperfusion (PCI), With a Special Focus on Upstream Use of Abciximab (EUROTRANSFER) Registry ${ }^{56}$ was a European, prospective, multicenter observational study including patients transferred (from a referral hospital or by pick-up from an ambulance) to a primary PCI center. The study was focused on the timing of abciximab application and related clinical outcomes. Early abciximab administration was associated with lower 30-day mortality and 30-day composite clinical end point compared to periprocedural abciximab administration. The difference was significant in favor of early abciximab, including after adjustment with multivariate regression and propensity score. ${ }^{56}$ In the additional analysis, based on patient risk profiles, the benefit of early abciximab administration was most pronounced in high-risk patients ( $\geq 3$ points in TIMI Risk Score).$^{57}$ Clinical outcome was also assessed in post hoc analysis of the Assessment of Pexelizumab in Acute Myocardial Infarction (APEX-AMI) trial, showing that pharmacological pretreatment with GP IIb/IIIa inhibitors (particularly with abciximab) was associated with a lower rate of 90-day clinical events. ${ }^{58}$ The strategy of early abciximab administration was shown to be superior over periprocedural administration in various subgroups of STEMI patients, including elderly and diabetic patients. ${ }^{59,60}$

The role of early GP IIb/IIIa administration was also assessed in several meta-analyses, two of which showed benefits from early pretreatment strategy assessed with surrogate, but not clinical, end points. ${ }^{61,62}$ Finally, the Early Glycoprotein IIb/IIIa Inhibitors in Primary Angioplasty (EGYPT) individual patient data meta-analysis (1,662 patients) was performed and showed that early administration of GP IIb/IIIa inhibitors before primary PCI for STEMI is associated with better preprocedural epicardial recanalization and ST-segment resolution after primary PCI. The nonsignificant reduction of mortality after early administration strategy was present in the whole population, but a significant mortality benefit was found when abciximab-treated patients were analyzed. ${ }^{63}$ Long-term results on early upstream administration of abciximab in STEMI patients were analyzed in the Early Glycoprotein IIb/IIIa Inhibitors in Primary AngioplastyAbciximab Long-Term Results (EGYPT-ALT) individual patient data meta-analysis and showed significant benefits in terms of pre- and postprocedural epicardial flow in IRA and postprocedural myocardial reperfusion (electrocardiographic ST-segment elevation resolution and angiographic myocardial blush grade), as well as mortality reduction at long-term follow-up (median of 1,095 days). ${ }^{64}$

In summary, in randomized studies, the strategy of early abciximab administration before angiography in patients with STEMI referred for primary PCI showed better results than periprocedural administration, but only on surrogate, and not on clinical, end points. Clinical benefit of early administration of abciximab (including mortality reduction) was confirmed by the EUROTRANSFER Registry results ${ }^{56}$ and metaanalyses. ${ }^{61-64}$ Importantly, early abciximab administration does not increase rate of bleeding compared to in-cath-lab administration. Based on ESC STEMI guidelines, upstream use of a GP IIb/IIIa inhibitor (versus in-lab use) may be considered in high-risk patients undergoing transfer for primary PCI. ${ }^{9}$ However, this strategy is currently less popular in daily practice, mostly due to improvements in the logistics of STEMI treatment (delay reduction) and introduction of new oral antiplatelet drugs (prasugrel and ticagrelor). It should be underlined that studies on early abciximab administration were performed in the era of clopidogrel treatment and, in a large proportion of those trials, clopidogrel was given after admission to a catheter laboratory. There are no data on early abciximab administration in patients treated with prasugrel and ticagrelor.

\section{Intracoronary versus intravenous administration}

In most cases, GP IIb/IIIa inhibitors, including abciximab, are used as intravenous bolus and infusion during primary PCI. On the other hand, during primary PCI, the intracoronary administration of abciximab can be easily performed using a guiding catheter, which may result in a more pronounced local inhibition of platelet function and a higher 
degree of GP IIb/IIIa receptor occupancy when compared to standard intravenous bolus injection. ${ }^{65}$ Single cases of dethrombotic effect using an intracoronary bolus have been reported. ${ }^{66-68}$ Initial nonrandomized studies suggested greater benefit from selective intracoronary administration using a guiding catheter. ${ }^{69,70}$ Further, in a small randomized study, intracoronary administration of abciximab during primary PCI improved reperfusion parameters and reduced infarct size in comparison with intravenous use. ${ }^{71}$ In addition, a trend toward a lower major adverse cardiac event rate at 30 days after intracoronary versus intravenous abciximab application was observed. ${ }^{71}$ To the contrary, the recently published randomized CICERO (Comparison of IntraCoronary versus intravenous abciximab administration during Emergency Reperfusion Of ST-segment elevation myocardial infarction) trial ${ }^{72}$ showed no benefit in terms of myocardial reperfusion and clinical outcome associated with intracoronary administration of abciximab in 534 patients with STEMI undergoing primary PCI. Additionally, the randomized Abciximab Intracoronary versus intravenously Drug Application in STEMI (AIDA STEMI) trial, ${ }^{73,74}$ including more than 2,000 patients, did not prove any benefit in reduction of clinical end points relating to intracoronary over intravenous administration of abciximab during shortand long-term follow-up. None of the secondary end points (including early ST-segment resolution, thrombolysis in myocardial infarction flow grade, and enzymatic infarct size) or safety measures differed significantly between groups. A cardiac magnetic resonance substudy of the AIDA STEMI $\operatorname{trial}^{75}$ demonstrated no benefit of intracoronary versus intravenous abciximab administration on myocardial damage and/or reperfusion injury. In a meta-analysis of eight studies including 3,259 patients, intracoronary administration of abciximab was associated with a significant improvement in myocardial perfusion, without significant benefits in terms of mortality, reinfarction, or major bleeding complications. ${ }^{76}$ However, a significant relationship was observed between a patient's risk profile and mortality benefits from intracoronary abciximab administration. Similarly, in a more recent pooled analysis of individual patient data from five randomized controlled trials (3,158 patients with STEMI), intracoronary abciximab administration was not associated with additional benefits compared with standard intravenous treatment. $^{77}$

Another administration option is intralesional infusion of abciximab using a dedicated therapeutic perfusion catheter. ${ }^{78}$ Local administration of abciximab may increase concentrations at the culprit lesion and in the distal vascular bed, as well as allow for optimization of the diffusion of abciximab to platelets within flow-limiting thrombi. Further, the non-GP IIb/IIIa properties of abciximab mediated through inhibition of the vibronectin and Mac-1 receptors may be greater at higher local concentrations. ${ }^{79}$ By potentiating the local anti-inflammatory effects of abciximab, reperfusion injury may be minimized, resulting in greater myocardial salvage. Data from the randomized ClearwayRx System to reduce intracoronary thrombus in patients with acute coronary syndromes according to Optical Coherence Tomography after Abciximab Intracoronary Local infusion (COCTAIL) study ${ }^{80}$ have shown that administration of abciximab by local intracoronary infusion through the ClearWay ${ }^{\mathrm{TM}} \mathrm{RX}$ (Atrium Medical Corporation, Hudson, NH, USA) catheter can reduce thrombus burden and improve coronary microcirculation. In the randomized INFUSE-AMI trial, ${ }^{33}$ local administration of abciximab with the ClearWay ${ }^{\mathrm{TM}} \mathrm{RX}$ catheter was associated with significant, albeit modest, reduction of the infarct size assessed by cardiac magnetic resonance at 30 days after first anterior wall STEMI in comparison to no abciximab administration. The highest benefit was observed when local infusion of abciximab was combined with prior thrombus aspiration. At 12 months, there was no difference in mortality, composite ischemic events, or heart failure-related events between patients treated with intralesion administration of abciximab and those without abciximab. ${ }^{81}$

Despite no clear clinical benefit from routine use of intracoronary or intralesional administration of abciximab, both constitute safe approaches for drug administration, although local delivery should generally be preferred over guide-catheter infusion to limit drug administration to non-culprit coronary arterial branches. Based on ACCF/ AHA guidelines for the management of STEMI, it may be reasonable to administer intracoronary abciximab to patients with STEMI undergoing primary PCI (class IIb, level of evidence B). ${ }^{11}$ Based on ESC STEMI guidelines, the intracoronary route may be considered, but the intravenous route should remain the standard of care for administration of GP IIb/IIIa inhibitors. ${ }^{9}$

\section{Future perspectives and ongoing studies}

Future studies will likely focus on the role of GP IIb/IIIa inhibitors in patients with STEMI pretreated with new oral $\mathrm{P} 2 \mathrm{Y}_{12}$ inhibitors. Given the limitations for immediate action of oral antiplatelet agents, a new intravenous $\mathrm{P} 2 \mathrm{Y}_{12}$ inhibitor - cangrelor - was introduced. In a meta-analysis of three randomized studies, cangrelor was shown to reduce 
periprocedural thrombotic complications of PCI as compared with control (clopidogrel or placebo). ${ }^{82}$ Despite excellent results with new oral $\mathrm{P} 2 \mathrm{Y}_{12}$ inhibitors, we can expect some head-to-head comparisons between abciximab and cangrelor in the near future. Further, the optimal technique for abciximab administration is still under investigation. For example, the COCTAIL II study ${ }^{83}$ aims to demonstrate that abciximab infusion with the ClearWay ${ }^{\mathrm{TM}} \mathrm{RX}$ catheter, with or without manual thrombus aspiration, will result in a significant reduction of intra-stent thrombus formations when compared with intravenous or intracoronary abciximab with or without thrombectomy. Additionally, the Thrombus aspiration for OccLuded coronary artery Enhanced with Distal injection Of abciximab (TOLEDO1) study (ClinicalTrials.gov identifier: NCT01383785) will assess the impact of distal injection of abciximab using a manual aspiration catheter after initial thrombus aspiration during primary PCI for STEMI. Future studies should also reevaluate the role of abciximab in patients treated with new stent designs (ie, mesh-covered stents, self-expandable stents) that are dedicated to lesions with a large thrombus burden. ${ }^{84,85}$

\section{Conclusion}

Currently, management of patients with STEMI involves not only mechanical restoration of the flow within the IRA, but also a system of early diagnosis and rapid transfer to PCI-capable centers; selection of optimal adjunctive pharmacotherapy (including timing and model of abciximab administration); and, finally, PCI procedure with dedicated devices. Abciximab may reduce the rate of clinical events, including mortality, in patients with STEMI, especially in high-risk patients. Thus, current guidelines recommend the selective use of abciximab for patients with a high risk of ischemic events (large anterior wall infarction, large thrombus burden) and/or angiographic complications (distal embolization, no reflow phenomenon) of primary PCI, especially in patients with a low risk of bleeding. Abciximab may also be considered in patients with expected delayed onset of action of oral antiplatelet drugs (patients with hemodynamic compromise, cardiogenic shock, cardiac arrest undergoing mild induced therapeutic hypothermia). On the other hand, the role of abciximab in patients with STEMI pretreated with new $\mathrm{P}_{12}$ inhibitors, which are becoming more and more popular, is not yet properly defined. The intracoronary route of administration of abciximab may be reasonable, with possible intralesional application in patients with a very large thrombus load at the site of IRA occlusion. To improve safety of the administration of abciximab, the use of a radial approach should be strongly considered in patients undergoing primary PCI.

\section{Disclosure}

Dariusz Dudek received a research grant as principal investigator of the EUROTRANSFER Registry and speaker fees from Eli Lilly and Company. Artur Dziewierz, and Tomasz Rakowski received travel grants and speaker fees from Eli Lilly and Company. The authors report no other conflicts of interest in this work.

\section{References}

1. Ibbotson T, McGavin JK, Goa KL. Abciximab: an updated review of its therapeutic use in patients with ischaemic heart disease undergoing percutaneous coronary revascularisation. Drugs. 2003;63(11): 1121-1163.

2. Brener SJ, Barr LA, Burchenal JE, et al. Randomized, placebo-controlled trial of platelet glycoprotein IIb/IIIa blockade with primary angioplasty for acute myocardial infarction. ReoPro and Primary PTCA Organization and Randomized Trial (RAPPORT) Investigators. Circulation. 1998;98(8):734-741.

3. Montalescot G, Barragan P, Wittenberg O, et al; ADMIRAL Investigators. Abciximab before Direct Angioplasty and Stenting in Myocardial Infarction Regarding Acute and Long-Term Follow-up. Platelet glycoprotein IIb/IIIa inhibition with coronary stenting for acute myocardial infarction. $N$ Engl J Med. 2001;344(25):1895-1903.

4. Stone GW, Grines CL, Cox DA, et al; Controlled Abciximab and Device Investigation to Lower Late Angioplasty Complications (CADILLAC) Investigators. Comparison of angioplasty with stenting, with or without abciximab, in acute myocardial infarction. N Engl J Med. 2002;346(13): 957-966.

5. Schömig A, Kastrati A, Dirschinger J, et al. Coronary stenting plus platelet glycoprotein IIb/IIIa blockade compared with tissue plasminogen activator in acute myocardial infarction. Stent versus Thrombolysis for Occluded Coronary Arteries in Patients with Acute Myocardial Infarction Study Investigators. $N$ Engl J Med. 2000;343(6):385-391.

6. De Luca G, Suryapranata H, Stone GW, et al. Abciximab as adjunctive therapy to reperfusion in acute ST-segment elevation myocardial infarction: a meta-analysis of randomized trials. JAMA. 2005;293(14): 1759-1765.

7. De Luca G, Ucci G, Cassetti E, Marino P. Benefits from small molecule administration as compared with abciximab among patients with ST-segment elevation myocardial infarction treated with primary angioplasty: a meta-analysis. J Am Coll Cardiol. 2009;53(18): 1668-1673.

8. Gurm HS, Tamhane U, Meier P, Grossman PM, Chetcuti S, Bates ER A comparison of abciximab and small-molecule glycoprotein IIb/IIIa inhibitors in patients undergoing primary percutaneous coronary intervention: a meta-analysis of contemporary randomized controlled trials. Circ Cardiovasc Interv. 2009;2(3):230-236.

9. Task Force on the management of ST-segment elevation acute myocardial infarction of the European Society of Cardiology (ESC), Steg PG, James SK, et al. ESC Guidelines for the management of acute myocardial infarction in patients presenting with ST-segment elevation. Eur Heart J. 2012;33(20):2569-2619.

10. Brener SJ. The benefits of platelet glycoprotein IIb/IIIa receptor inhibition during primary percutaneous coronary intervention for ST-segment elevation myocardial infarction: drug-specific or class effect? J Am Coll Cardiol. 2009;53(18):1674-1676.

11. American College of Emergency Physicians; Society for Cardiovascular Angiography and Interventions, O’Gara PT, Kushner FG, et al. 2013 ACCF/AHA guideline for the management of ST-elevation myocardial infarction: a report of the American College of Cardiology Foundation/ American Heart Association Task Force on Practice Guidelines. J Am Coll Cardiol. 2013;61(4):e78-e140. 
12. Subherwal S, Peterson ED, Dai D, et al. Temporal trends in and factors associated with bleeding complications among patients undergoing percutaneous coronary intervention: a report from the National Cardiovascular Data CathPCI Registry. JAm Coll Cardiol. 2012;59(21): 1861-1869.

13. Dudek D, Legutko J, Siudak Z, et al. [Interventional cardiology in Poland in the year 2012. Summary report of the Association of Cardiovascular Interventions of the Polish Cardiac Society]. Kardiol Pol. 2013;71(11):1213-1219. Polish.

14. Stone GW, Witzenbichler B, Guagliumi G, et al; HORIZONS-AMI Trial Investigators. Heparin plus a glycoprotein IIb/IIIa inhibitor versus bivalirudin monotherapy and paclitaxel-eluting stents versus baremetal stents in acute myocardial infarction (HORIZONS-AMI): final 3 -year results from a multicentre, randomised controlled trial. Lancet. 2011;377(9784):2193-2204.

15. Stone GW, Witzenbichler B, Guagliumi G, et al; HORIZONS-AMI Trial Investigators. Bivalirudin during primary PCI in acute myocardial infarction. N Engl J Med. 2008;358(21):2218-2230.

16. Steg PG, van 't Hof A, Hamm CW, et al; EUROMAX Investigators. Bivalirudin started during emergency transport for primary PCI. N Engl J Med. 2013;369(23):2207-2217.

17. Wiviott SD, Trenk D, Frelinger AL, et al; PRINCIPLE-TIMI 44 Investigators. Prasugrel compared with high loading- and maintenancedose clopidogrel in patients with planned percutaneous coronary intervention: the Prasugrel in Comparison to Clopidogrel for Inhibition of Platelet Activation and Aggregation-Thrombolysis in Myocardial Infarction 44 trial. Circulation. 2007;116(25):2923-2932.

18. Michelson AD, Frelinger AL 3rd, Braunwald E, et al; TRITON-TIMI 38 Investigators. Pharmacodynamic assessment of platelet inhibition by prasugrel vs clopidogrel in the TRITON-TIMI 38 trial. Eur Heart $J$. 2009;30(14):1753-1763.

19. Gurbel PA, Bliden KP, Butler K, et al. Randomized double-blind assessment of the ONSET and OFFSET of the antiplatelet effects of ticagrelor versus clopidogrel in patients with stable coronary artery disease: the ONSET/OFFSET study. Circulation. 2009;120(25):2577-2585.

20. Tantry US, Budaj A, Gurbel PA. Antiplatelet therapy beyond 2012: role of personalized medicine. Pol Arch Med Wewn. 2012;122(6): 298-305.

21. Wiviott SD, Braunwald E, McCabe CH, et al; TRITON-TIMI 38 Investigators. Prasugrel versus clopidogrel in patients with acute coronary syndromes. $N$ Engl J Med. 2007;357(20):2001-2015.

22. Wallentin L, Becker RC, Budaj A, et al; PLATO Investigators, Freij A, Thorsén M. Ticagrelor versus clopidogrel in patients with acute coronary syndromes. $N$ Engl J Med. 2009;361(11):1045-1057.

23. O’Donoghue M, Antman EM, Braunwald E, et al. The efficacy and safety of prasugrel with and without a glycoprotein IIb/IIIa inhibitor in patients with acute coronary syndromes undergoing percutaneous intervention: a TRITON-TIMI 38 (Trial to Assess Improvement in Therapeutic Outcomes by Optimizing Platelet Inhibition With Prasugrel-Thrombolysis In Myocardial Infarction 38) analysis. $J$ Am Coll Cardiol. 2009;54(8):678-685.

24. Rakowski T, Dziewierz A, Siudak Z, Kleczyński P, Dubiel JS, Dudek D. Introduction of new oral antiplatelet drugs in myocardial infarction hospital network: initial experience. JThromb Thrombolysis. 2014;37(3):243-245.

25. Alexopoulos D, Xanthopoulou I, Deftereos S, et al. In-hospital switching of oral P2Y12 inhibitor treatment in patients with acute coronary syndrome undergoing percutaneous coronary intervention: prevalence, predictors and short-term outcome. Am Heart J. 2014;167(1): 68-76.

26. Valgimigli M, Tebaldi M, Campo G, et al; FABOLUS PRO Investigators. Prasugrel versus tirofiban bolus with or without short post-bolus infusion with or without concomitant prasugrel administration in patients with myocardial infarction undergoing coronary stenting: the FABOLUS PRO (Facilitation through Aggrastat By drOpping or shortening Infusion Line in patients with ST-segment elevation myocardial infarction compared to or on top of PRasugrel given at loading dOse) trial. JACC Cardiovasc Interv. 2012;5(3):268-277.
27. Osmancik P, Jirmar R, Hulikova K, et al. A comparison of the VASP index between patients with hemodynamically complicated and uncomplicated acute myocardial infarction. Catheter Cardiovasc Interv. 2010;75(2):158-166.

28. Fuernau G, Thiele H. The spectrum of haemodynamic support in cardiogenic shock: how to choose and use. Kardiol Pol. 2013;71(9): 887-892.

29. Ibrahim K, Christoph M, Schmeinck S, et al. High rates of prasugrel and ticagrelor non-responder in patients treated with therapeutic hypothermia after cardiac arrest. Resuscitation. 2014;85(5): 649-656.

30. Noc M, Knafelj R, Mrevlje B. Urgent invasive coronary strategy and mild induced hypothermia in patients with resuscitated sudden cardiac arrest. Kardiol Pol. 2013;71(3):286-289.

31. Bittl JA. Abciximab during percutaneous coronary intervention for STsegment elevation myocardial infarction: intracoronary, intravenous, or not at all? J Am Coll Cardiol. 2013;61(13):1455-1457.

32. Burzotta F, De Vita M, Gu YL, et al. Clinical impact of thrombectomy in acute ST-elevation myocardial infarction: an individual patient-data pooled analysis of 11 trials. Eur Heart J. 2009;30(18):2193-2203.

33. Stone GW, Maehara A, Witzenbichler B, et al; INFUSE-AMI Investigators. Intracoronary abciximab and aspiration thrombectomy in patients with large anterior myocardial infarction: the INFUSE-AMI randomized trial. JAMA. 2012;307(17):1817-1826.

34. De Luca G, Navarese E, Marino P. Risk profile and benefits from Gp IIb-IIIa inhibitors among patients with ST-segment elevation myocardial infarction treated with primary angioplasty: a meta-regression analysis of randomized trials. Eur Heart J. 2009;30(22):2705-2713.

35. Iqbal Z, Cohen M, Pollack C, et al; ATOLL Investigators. Safety and efficacy of adjuvant glycoprotein IIb/IIIa inhibitors during primary percutaneous coronary intervention performed from the radial approach for acute ST segment elevation myocardial infarction. Am J Cardiol. 2013;111(12):1727-1733.

36. [No authors listed]. Use of a monoclonal antibody directed against the platelet glycoprotein IIb/IIIa receptor in high-risk coronary angioplasty. The EPIC Investigation. $N$ Engl J Med. 1994;330(14): 956-961.

37. Topol EJ, Califf RM, Weisman HF, et al. Randomised trial of coronary intervention with antibody against platelet IIb/IIIa integrin for reduction of clinical restenosis: results at six months. Lancet. 1994;343(8902):881-886.

38. Valgimigli M, Campo G, Tebaldi M, et al; Fabolus Synchro (facilitation through abciximab by dropping infusion Line in patients undergoing coronary stenting. Synergy with clopidogrel at high loading dose regimen) Investigators. Randomized, double-blind comparison of effects of abiciximab bolus only vs on-label regimen on ex vivo inhibition of platelet aggregation in responders to clopidogrel undergoing coronary stenting. J Thromb Haemost. 2010;8(9):1903-1911.

39. Christ G, Hafner T, Siller-Matula JM, et al. Platelet inhibition by abciximab bolus-only administration and oral ADP receptor antagonist loading in acute coronary syndrome patients: the blocking and bridging strategy. Thromb Res. 2013;132(1):e36-e41.

40. van den Merkhof LF, Zijlstra F, Olsson H, et al. Abciximab in the treatment of acute myocardial infarction eligible for primary percutaneous transluminal coronary angioplasty. Results of the Glycoprotein Receptor Antagonist Patency Evaluation (GRAPE) pilot study. J Am Coll Cardiol. 1999;33(6):1528-1532.

41. Makkar R, Goff B, Eigler N, et al. Effect of glycoprotein IIb/IIIa inhibition without thrombolytic therapy on reperfusion in acute myocardial infarction: results of ReoMI pilot study. Catheter Cardiovasc Interv. 1999;48(4):430-434.

42. Zorman S, Zorman D, Noc M. Effects of abciximab pretreatment in patients with acute myocardial infarction undergoing primary angioplasty. Am J Cardiol. 2002;90(5):533-536.

43. Gyöngyösi M, Domanovits H, Benzer W, et al; ReoPro-BRIDGING Study Group. Use of abciximab prior to primary angioplasty in STEMI results in early recanalization of the infarct-related artery and improved myocardial tissue reperfusion - results of the Austrian multi-centre randomized ReoPro-BRIDGING Study. Eur Heart J. 2004;25(23):2125-2133. 
44. Bellandi F, Maioli M, Leoncini M, Toso A, Dabizzi RP. Early abciximab administration in acute myocardial infarction treated with primary coronary intervention. Int J Cardiol. 2006;108(1):36-42.

45. Rakowski T, Zalewski J, Legutko J, et al. Early abciximab administration before primary percutaneous coronary intervention improves infarctrelated artery patency and left ventricular function in high-risk patients with anterior wall myocardial infarction: a randomized study. Am Heart J. 2007;153(3):360-365.

46. Maioli M, Bellandi F, Leoncini M, Toso A, Dabizzi RP. Randomized early versus late abciximab in acute myocardial infarction treated with primary coronary intervention (RELAx-AMI Trial). JAm Coll Cardiol. 2007;49(14):1517-1524

47. Dudek D, Rakowski T, Bartus S, et al. Impact of early abciximab administration on myocardial reperfusion in patients with ST-segment elevation myocardial infarction pretreated with $600 \mathrm{mg}$ of clopidogrel before percutaneous coronary intervention. J Thromb Thrombolysis. 2010;30(3):347-353.

48. Ohlmann P, Reydel P, Jacquemin L, et al. Prehospital abciximab in STsegment elevation myocardial infarction: results of the randomized, doubleblind MISTRAL study. Circ Cardiovasc Interv. 2012;5(1): 69-76, S1.

49. Gabriel HM, Oliveira JA, da Silva PC, da Costa JM, da Cunha JA. Early administration of abciximab bolus in the emergency department improves angiographic outcome after primary PCI as assessed by TIMI frame count: results of the early ReoPro administration in myocardial infarction (ERAMI) trial. Catheter Cardiovasc Interv. 2006;68(2):218-224.

50. Pels K, Schröder J, Witzenbichler B, et al. Prehospital versus periprocedural abciximab in ST-elevation myocardial infarction treated by percutaneous coronary intervention. Eur J Emerg Med. 2008;15(6): 324-329.

51. Rakowski T, Mielecki W, Brzozowska-Czarnek A, et al. Effects of early abciximab administration before primary percutaneous coronary intervention on left ventricular function assessed by cardiac magnetic resonance. Kardiol Pol. 2008;66(6):617-622.

52. Hassan AK, Liem SS, van der Kley F, et al. In-ambulance abciximab administration in STEMI patients prior to primary PCI is associated with smaller infarct size, improved LV function and lower incidence of heart failure: results from the Leiden MISSION! acute myocardial infarction treatment optimization program. Catheter Cardiovasc Interv. 2009;74(2):335-343

53. Petronio AS, De Carlo M, Strata E, et al. Impact of early abciximab administration on infarct size in patients with ST-elevation myocardial infarction. Int J Cardiol. 2012;155(2):230-235.

54. Ellis SG, Tendera M, de Belder MA, et al; FINESSE Investigators. Facilitated PCI in patients with ST-elevation myocardial infarction. N Engl J Med. 2008;358(21):2205-2217.

55. Herrmann HC, Lu J, Brodie BR, et al; FINESSE Investigators. Benefit of facilitated percutaneous coronary intervention in high-risk ST-segment elevation myocardial infarction patients presenting to nonpercutaneous coronary intervention hospitals. JACC Cardiovasc Interv. 2009;2(10):917-924.

56. Dudek D, Siudak Z, Janzon M, et al; EUROTRANSFER Registry Investigators. European registry on patients with ST-elevation myocardial infarction transferred for mechanical reperfusion with a special focus on early administration of abciximab - EUROTRANSFER Registry. Am Heart J. 2008;156(6):1147-1154.

57. Rakowski T, Siudak Z, Dziewierz A, et al. Early abciximab administration before transfer for primary percutaneous coronary interventions for ST-elevation myocardial infarction reduces 1-year mortality in patients with high-risk profile. Results from EUROTRANSFER registry. Am Heart J. 2009;158(4):569-575.

58. Huber K, Holmes DR Jr, van 't Hof AW, et al. Use of glycoprotein IIb/IIIa inhibitors in primary percutaneous coronary intervention: insights from the APEX-AMI trial. Eur Heart J. 2010;31(14):1708-1716.

59. Dziewierz A, Siudak Z, Rakowski T, et al. Early abciximab administration before primary percutaneous coronary intervention improves clinical outcome in elderly patients transferred with ST-elevation myocardial infarction: data from the EUROTRANSFER registry. Int J Cardiol. 2010;143(2):147-153.
60. Dziewierz A, Mielecki W, Siudak Z, et al. Early abciximab administration before primary percutaneous coronary intervention improves clinical outcome in diabetic patients with ST-segment elevation myocardial infarction (EUROTRANSFER Registry). Atherosclerosis. 2012;223(1):212-218.

61. Montalescot G, Borentain M, Payot L, Collet JP, Thomas D. Early vs late administration of glycoprotein IIb/IIIa inhibitors in primary percutaneous coronary intervention of acute ST-segment elevation myocardial infarction: a meta-analysis. JAMA. 2004;292(3): 362-366.

62. Gödicke J, Flather M, Noc M, et al. Early versus periprocedural administration of abciximab for primary angioplasty: a pooled analysis of 6 studies. Am Heart J. 2005;150(5):1015.

63. De Luca G, Gibson CM, Bellandi F, et al. Early glycoprotein IIb-IIIa inhibitors in primary angioplasty (EGYPT) cooperation: an individual patient data meta-analysis. Heart. 2008;94(12):1548-1558.

64. De Luca G, Bellandi F, Huber K, et al. Early glycoprotein IIb-IIIa inhibitors in primary angioplasty-abciximab long-term results (EGYPT-ALT) cooperation: individual patient's data meta-analysis. J Thromb Haemost. 2011;9(12):2361-2370.

65. Desch S, Siegemund A, Scholz U, et al. Platelet inhibition and GP IIb/IIIa receptor occupancy by intracoronary versus intravenous bolus administration of abciximab in patients with ST-elevation myocardial infarction. Clin Res Cardiol. 2012;101(2):117-124.

66. Bailey SR, O’Leary E, Chilton R. Angioscopic evaluation of site-specific administration of ReoPro. Cathet Cardiovasc Diagn. 1997;42(2):181-184.

67. Barsness GW, Buller C, Ohman EM, et al. Reduced thrombus burden with abciximab delivered locally before percutaneous intervention in saphenous vein grafts. Am Heart J. 2000;139(5):824-829.

68. Schlaifer JD, Horgan W, Malkowski MJ. Acute thrombotic occlusion of the left main coronary artery in a hypercoagulable patient treated with intracoronary abciximab. Clin Cardiol. 2001;24(12):788.

69. Wöhrle J, Grebe OC, Nusser T, et al. Reduction of major adverse cardiac events with intracoronary compared with intravenous bolus application of abciximab in patients with acute myocardial infarction or unstable angina undergoing coronary angioplasty. Circulation. 2003;107(14): 1840-1843.

70. Kakkar AK, Moustapha A, Hanley HG, et al. Comparison of intracoronary vs intravenous administration of abciximab in coronary stenting. Catheter Cardiovasc Interv. 2004;61(1):31-34.

71. Thiele H, Schindler K, Friedenberger J, et al. Intracoronary compared with intravenous bolus abciximab application in patients with ST-elevation myocardial infarction undergoing primary percutaneous coronary intervention: the randomized Leipzig immediate percutaneous coronary intervention abciximab IV versus IC in ST-elevation myocardial infarction trial. Circulation. 2008;118(1):49-57.

72. Gu YL, Kampinga MA, Wieringa WG, et al. Intracoronary versus intravenous administration of abciximab in patients with ST-segment elevation myocardial infarction undergoing primary percutaneous coronary intervention with thrombus aspiration: the comparison of intracoronary versus intravenous abciximab administration during emergency reperfusion of ST-segment elevation myocardial infarction (CICERO) trial. Circulation. 2010;122(25):2709-2717.

73. Thiele H, Wöhrle J, Hambrecht R, et al. Intracoronary versus intravenous bolus abciximab during primary percutaneous coronary intervention in patients with acute ST-elevation myocardial infarction: a randomised trial. Lancet. 2012;379(9819):923-931.

74. Desch S, Wöhrle J, Hambrecht R, et al. Intracoronary versus intravenous abciximab bolus in patients with ST-segment elevation myocardial infarction: 1-year results of the randomized AIDA STEMI trial. J Am Coll Cardiol. 2013;62(13):1214-1215.

75. Eitel I, Wöhrle J, Suenkel H, et al. Intracoronary compared with intravenous bolus abciximab application during primary percutaneous coronary intervention in ST-segment elevation myocardial infarction: cardiac magnetic resonance substudy of the AIDA STEMI trial. J Am Coll Cardiol. 2013;61(13):1447-1454. 
76. De Luca G, Verdoia M, Suryapranata H. Benefits from intracoronary as compared to intravenous abciximab administration for STEMI patients undergoing primary angioplasty: a meta-analysis of 8 randomized trials. Atherosclerosis. 2012;222(2):426-433.

77. Piccolo R, Eitel I, Iversen AZ, et al. Intracoronary versus intravenous bolus abciximab administration in patients undergoing primary percutaneous coronary intervention with acute ST-elevation myocardial infarction: a pooled analysis of individual patient data from five randomised controlled trials. EuroIntervention. 2014;9(9): $1110-1120$

78. Dziewierz A, Brzeziński M, Rakowski T, Dudek D. Local administration of abciximab using a ClearWay RX infusion catheter in a patient with acute coronary syndrome caused by late in-stent thrombosis. Kardiol Pol. 2012;70(11):1199-1201.

79. Romagnoli E, Burzotta F, Trani C, Biondi-Zoccai GG, Giannico F, Crea F. Rationale for intracoronary administration of abciximab. J Thromb Thrombolysis. 2007;23(1):57-63.

80. Prati F, Capodanno D, Pawlowski T, et al. Local delivery versus intracoronary infusion of abciximab in patients with acute coronary syndromes. JACC Cardiovasc Interv. 2010;3(9):928-934.
81. Stone GW, Witzenbichler B, Godlewski J, et al. Intralesional abciximab and thrombus aspiration in patients with large anterior myocardial infarction: one-year results from the INFUSE-AMI trial. Circ Cardiovasc Interv. 2013;6(5):527-534.

82. Steg PG, Bhatt DL, Hamm CW, et al; CHAMPION Investigators. Effect of cangrelor on periprocedural outcomes in percutaneous coronary interventions: a pooled analysis of patient-level data. Lancet. 2013;382(9909):1981-1992.

83. Prati F, Di Vito L, Ramazzotti V, et al. Randomized trial of standard versus ClearWay-infused abciximab and thrombectomy in myocardial infarction: rationale and design of the COCTAIL II study. J Cardiovasc Med (Hagerstown). 2013;14(5):364-371.

84. Dudek D, Dziewierz A, Kleczyński P, et al. Long-term follow-up of mesh-covered stent implantation in patients with ST-segment elevation myocardial infarction. Kardiol Pol. 2014;72(2):140-145.

85. Dziewierz A, Dudek D. Advantages of MGuard coronary stent system. Minerva Cardioangiol. 2012;60(1):33-40.
Therapeutics and Clinical Risk Management

\section{Publish your work in this journal}

Therapeutics and Clinical Risk Management is an international, peerreviewed journal of clinical therapeutics and risk management, focusing on concise rapid reporting of clinical studies in all therapeutic areas, outcomes, safety, and programs for the effective, safe, and sustained use of medicines. This journal is indexed on PubMed Central, CAS,

\section{Dovepress}

EMBase, Scopus and the Elsevier Bibliographic databases. The manuscript management system is completely online and includes a very quick and fair peer-review system, which is all easy to use. Visit http://www.dovepress.com/testimonials.php to read real quotes from published authors.

Submit your manuscript here: http://www.dovepress.com/therapeutics-and-clinical-risk-management-journal 